\title{
STUDYING THE STRUCTURE OF THE ELEMENTS OF THE CABLE OF TECHNICAL SUPERCONDUCTORS BY ATOMIC FORCE MICROSCOPY
}

\author{
S. A. Barannikova ${ }^{1,2}$, G. V. Shlyakhova ${ }^{1,3}$, L. B. Zuev ${ }^{1,2}$ \\ ${ }^{1}$ Institute of Strength Physics and Materials Science of Siberian Branch Russian Academy of Sciences; \\ (ISPMS SBRAS); Address: 2/4, pr. Akademicheskii, Tomsk, 634055, Russia \\ ${ }^{2}$ National Research Tomsk State University (TSU), 36 Lenin Prospekt, Tomsk, 634050, Russia \\ ${ }^{3}$ Seversk Technological Institute - branch of State Autonomous Educational Institution of Higher Professional \\ Education «National Research Nuclear University «MEPHI» (STI NRNU MEPhl); Address: 65, \\ Communistic prospectus, Seversk, 636036, Russia \\ * Corresponding author. E-mail: bsa@,ispms.tsc.ru; address for correspondence: ISPMS SBRAS, 2/4, \\ pr. Akademicheskii, Tomsk, 634055, Russia. Tel.: +7 3822286923
}

Microstructural evolution in a superconductive cable made of the $\mathrm{Nb}+47 \% \mathrm{Ti}$ alloy and drawn to obtain intermediate reduction from $\varnothing 1.3$ to $\varnothing 1.2 \mathrm{~mm}$ is studied by atomic force, optical and electron microscopies. This alloy is used for making current-carrying elements in the magnetic system of the International Thermonuclear Experimental Reactor (ITER). The aim of the paper is to analyze the effect of cold deformation by drawing on the structure of a $\mathrm{Nb}$-Ti alloy-based multicore superconductor. The microstructures have been examined, as well as the effect they have on the properties of the cold-drawn superconductive $\mathrm{Nb}$-Ti alloy. The micro structural parameters, such as grain and subgrain sizes, phase and chemical homogeneity of the grains, have been determined. Strain localization zones have been revealed in the sites of wire breakage. Changes in the chemical composition of $\mathrm{Nb}$-Ti wires in defect-free breakage zones have been detected. It has been found that a diffusion $\mathrm{Nb}$ barrier is formed around the $\mathrm{Nb}$-Ti wire placed in the copper binder.

Keywords: superconductors, defects, microstructure.

DOI: $10.17804 / 2410-9908.2016 .1 .007-015$

\section{References}

1. Ginzburg V.L., Andryushin E.A. Sverkhprovodimost [Superconductivity]. Moscow, Alfa-M Publ., 2006, 110 p. (In Russian).

2. $\quad$ Shikov A.K., Nikulin A.D., Silaev A.G., Pantsyrnyi V.I., Vedernikov G.P., Dergunova E.A., Potanina L.V., Plashkin E.I., Sudyev S.V. Development of superconductors for the magnetic system of ITER in Russia. Izvestiya vuzov. Tsvetnaya metallurgiya, 2003, no. 1, pp. 36-43. (In Russian).

3. Kozlenkova Nina I., Vedernikov Gennadi P., Shikov Alexander K., Potanina Ludmila V., Filatov Alexei V., Vorobieva Alexandra E., Pantsyrnyi Viktor I., Gubkin Igor N. Study on $\mathrm{I}_{\mathrm{c}}(\mathrm{T}, \mathrm{B})$ for the $\mathrm{NbTi}$ Strand Intended for ITER PF Insert Coil. IEEE Transactions on Applied Superconductivity, 2004, vol. 14, no. 2, pp. 1028-1030. DOI: 10.1109/TASC.2004.830385.

4. Lee P.J., Larbalestier D.C. Development of nanometer scale structures in composites of $\mathrm{NbTi}$ and their effect on the superconducting critical current density. Acta Metallurgica, 1987, vol. 35, iss. 10, pp. 2523-2536. DOI:10.1016/0001-6160(87)90149-0.

5. Cherny O.V., Tikhinsky G.F., Storozhilov G.E., Lazareva M.B., Kornienko L.A., Andrievskaya N.F., Slezov V.V., Sagalovich V.V., Starodubov Ya.D., Savchenko V.I. Niobiumtitanium superconductors with high current-carrying ability. Sverkhprovodimost. Fizika, khimiya, tekhnika, 1991, vol. 4, no. 8, pp. 1617-1623. (In Russian).

6. Mironov V.L. Osnovy skaniruyushchei zondovoi mikroskopii [Foundations of Scanning Probe Microscopy]. N. Novgorod, IFM RAN Publ., 2004, 110 p. (In Russian).

7. Zuev L.B., Shlyakhova G.V., Barannikova S.A., Kolosov S.V. Research of a microstructure of elements of a cable from a superconducting alloy of Nb-Ti. Russian Metallurgy, 2013, vol. 2013, iss. 3, pp. 229-234. DOI: 10.1134/S0036029513030129.

Barannikova S.A. et al. / Studying the structure of the elements of the cable of technical superconductors by atomic force microscopy 
8. Shlyakhova G.V., Barannikova S.A., Zuev L.B. Studying the fine structure of the elements of technical superconducting cables. Fizika i khimiya obrabotki materialov, 2014, no. 4, pp. 80-88. (In Russian).

9. Shlyakhova G.V., Barannikova S.A., Zuev L.B. Studying the nanostructural elements of the cable of technical Nb-Ti superconductors. Izvestiya Vuzov. Chernaya Metallurgiya, 2013, no. 10, pp. 64-67. (In Russian).

10. Shlyakhova G.V., Barannikova S.A., Zuev L.B. Studying the centers of plastic strain localization in a Nb-Ti-based superconducting cable. Metallofizika i noveishie tekhnologii, 2013, vol. 35, no. 4, pp. 453-465. (In Russian).

11. Zuev L.B., Zavodchikov S.Y., Poletika T.M., Cheremnykh G.S., Filippov V.B., Belov V.I., Arzhakova V.M., Bocharov O.V., Shikov A.K. Phase composition, structure and plastic deformation localization in $\mathrm{Zr} 1 \% \mathrm{Nb}$ alloy. In: P. Rudling, B. Kammenzind, eds. Proceedings of 14th International Symposium on Zirconium in the Nuclear Industry. West Conshohocken, ASTM, 2006, pp. 264-274. DOI: 10.1520/STP37511S.

12. Zuev L.B., Danilov V.I., Barannikova S.A. Fizika makrolokalizatsii plasticheskogo techeniya [Physics of Plastic Flow Macrolocalization]. Novosibirsk, Nauka Publ., 2008. 327 p. (In Russian).

13. Zuev L.B., Barannikova S.A. Experimental study of plastic flow macro-scale localization process: pattern, propagation rate, dispersion. International Journal of Mechanical Sciences, 2014, vol. 88, pp. 1-7. DOI: 10.1016/j.ijmecsci.2014.06.012.УДК 620.186/187 
Подана в журнал: 25.12 .2015

УДК $620.186 / 187$

DOI: $10.17804 / 2410-9908.2016 .1 .007-015$

\title{
ИССЛЕДОВАНИЕ СТРУКТУРЫ ЭЛЕМЕНТОВ КАБЕЛЯ ТЕХНИЧЕСКИХ СВЕРХПРОВОДНИКОВ МЕТОДАМИ АТОМНО-СИЛОВОЙ МИКРОСКОПИИ
}

\author{
С.А. Баранникова ${ }^{1,2}$, ,Г.В. Шляхова ${ }^{1,3}$, Л.Б. Зуев ${ }^{1,2}$ \\ ${ }^{1}$ Институт физики прочности и материаловедения СО РАН, 634055, г. Томск, пр. Академический 2/4, Россия \\ ${ }^{2}$ Национальный исследовательский Томский государственный университет, \\ 634050, г. Томск, пр. Ленина, 36, Россия \\ ${ }^{3}$ Северский технологический институт - филиал НИЯУ МИФИ, 636036, Томская область, г. Северск, \\ пр. Коммунистический, 65, Россия \\ *Ответственный автор. E-mail: bsa@ispms.tsc.ru; ИФПМ CO РАН, 634055, г. Томск, пр. Академический 2/4, \\ Россия. Телефон: 8 (3822) 286-923
}

Методами атомно-силовой, электронной и оптической микроскопии исследована эволюция структуры на промежуточной стадии волочения при переходе Ø1,3 $\rightarrow \varnothing 1,2$ мм сверхпроводящего кабеля на основе сплава ниобий-титан $(\mathrm{Nb}+47 \%$ Ti), который используется в качестве токонесущих элементов в магнитной системе Международного термоядерного экспериментального реактора (ИТЭР). Цель работы - анализ влияния холодной деформации волочением на структуру многожильного сверхпроводника на основе сплава $\mathrm{Nb}$-Ti. Исследованы микроструктуры и их влияние на свойства сверхпроводящего сплава $\mathrm{Nb}$-Ті после холодного волочения. Определены такие структурные параметры, как размеры зерен и субзерен. Выявлены зоны локализации пластической деформации в местах обрывов сверхпроводника. Обнаружено изменение формы волокон $\mathrm{Nb}$ - $\mathrm{Ti}$ в бездефектной области и в зоне разрыва кабеля. Выявлен диффузионный $\mathrm{Nb}$ барьер вокруг волокон $\mathrm{Nb}-\mathrm{Ti}$, размещенных в медной матрице.

Ключевые слова: сверхпроводники, дефекты, микроструктура.

\section{1. Введение}

Практика использования сверхпроводников позволяет решить ряд важных технических проблем в тех областях техники, где применение традиционных электротехнических материалов экономически нецелесообразно или принципиально невозможно. Среди различных сверхпроводящих материалов сплав $\mathrm{Nb}-\mathrm{Ti}$, используемый для изготовления токонесущих элементов в магнитной системе Международного термоядерного экспериментального реактора (ИТЭР), занимает особое положение [1]. Конструкция сверхпроводящего кабеля состоит из нескольких тысяч сверхпроводящих жил диаметром 2...5 мкм, фиксируемых медной матрицей [2]. К таким кабелям предъявляются высокие требования, наиболее важными из которых являются величина и стабильность критических параметров, стабильность токовых характеристик, безобрывность сверхпроводящих волокон (жил), их структурная однородность по длине провода и малые отклонения от геометрических размеров поперечного сечения [3-5].

При производстве проводников из сверхпроводящего сплава $\mathrm{Nb}$-Ti наиболее ответственным этапом является холодное волочение, в ходе которого исходная композиционная заготовка деформируется от $\varnothing 60 \ldots 70$ мм до Ø0,1...1,0 мм. На этом этапе необходимо обеспечить безобрывность процесса и заданную плотность микродефектов в сверхпроводнике, контролирующих образование центров пиннинга (закрепления магнитных вихрей Абрикосова в сверхпроводниках II рода) [1]. 
Настоящая работа направлена на анализ влияния холодной деформации волочением на структуру многожильного сверхпроводника на основе сплава $\mathrm{Nb}-\mathrm{Ti}$.

\section{2. Материалы и методика}

Деформационная структура и субструктура многожильного кабеля со сверхпроводящими жилами из сплава $\mathrm{Nb}-47,5$ мас.\%Ті исследовалась на промежуточной стадии волочения при переходе $\varnothing 1,3 \rightarrow \varnothing 1,2$ мм. Для анализа состава и структуры композитного многожильного провода использовалось несколько методик, обеспечивающих необходимое пространственное разрешение: оптическая микроскопия (Neophot-21 и Olympus GX 71), атомно-силовая микроскопия (Solver PH47-PRO) с использованием контактного метода.

\section{3. Результаты и обсуждение}

Многожильный сверхпроводящий кабель на основе сплава Nb-Ti представляет собой трехслойную конструкцию, в которой между медными сердечником и внешней оболочкой располагается промежуточный слой из волокон $\mathrm{Nb}-\mathrm{Ti}$, размещенных в медной матрице (композит) (рис. 1). Такой композит может также содержать резистивные или диффузионные барьеры, стабилизирующие оболочки и прочные армирующие элементы [2].

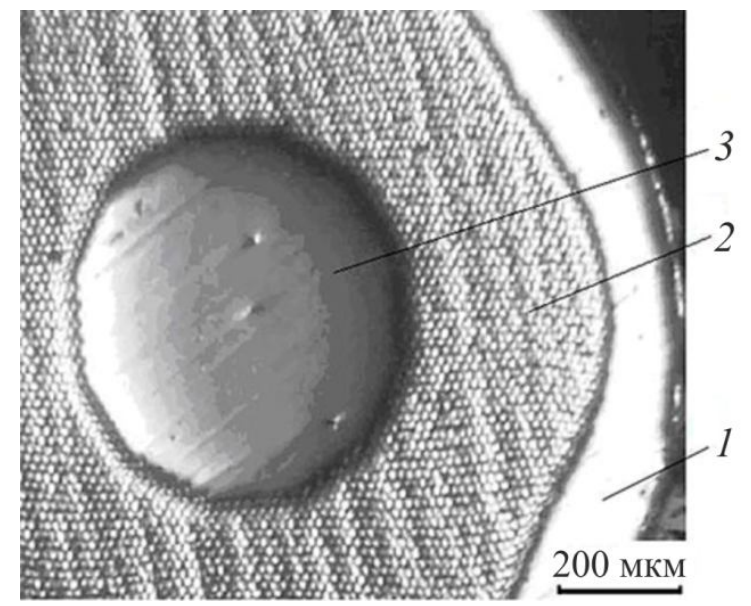

Рис. 1. Поперечное сечение кабеля технических сверхпроводников $\mathrm{Nb}-\mathrm{Ti}$ на промежуточной стадии волочения при переходе Ø1,3 $\rightarrow \varnothing 1,2$ мм: 1 - медная оболочка; 2 - волокна $\mathrm{Nb}-\mathrm{Ti}$; 3 - медный сердечник

Для более точного выявления рельефа поперечных сечений элементов кабеля использовали атомно-силовую микроскопию с применением контактного метода в режиме "постоянной силы“ [6]. В результате сканирования вокруг волокон $\mathrm{Nb}-\mathrm{Ti}$, размещенных в медной матрице, выявлен диффузионный $\mathrm{Nb}$ барьер, который отчетливо проявляется в виде выступов рельефа в зоне сопряжения жилы с матрицей (рис. 2 a).

На профилограмме, построенной методом секущих, ниобиевый барьер выявляется по высокоамплитудным максимумам шириной до $250 \ldots 260$ нм, разделенных низкоамплитудными линиями рельефа для волокон $\mathrm{Nb}-\mathrm{Ti}$ и медной матрицы (рис. 2 б, в).

В результате интенсивной пластической деформации медь в сердечнике приобретает субмикрокристаллическую структуру со средним размером зерен $\sim 800$ нм. В такой структуре чередуются одиночные зерна и их конгломераты, насчитывающие до 8 зерен. Сильнее всего медь в сердечнике продеформирована по границе сердечник - промежуточный слой проводника, где максимальный размер зерна составил 2120 нм, а минимальный 310 нм. В промежуточном слое между волокнами в матрице медь представлена равноосными зернами

Barannikova S.A. et al. / Studying the structure of the elements of the cable of technical superconductors by atomic force microscopy 
ittp://dream-journal.or"

со средним размером $~ 800$ нм. В то же время средний размер зерен меди в оболочке проводпроводника составил $\sim 1050$ нм [7, 8].

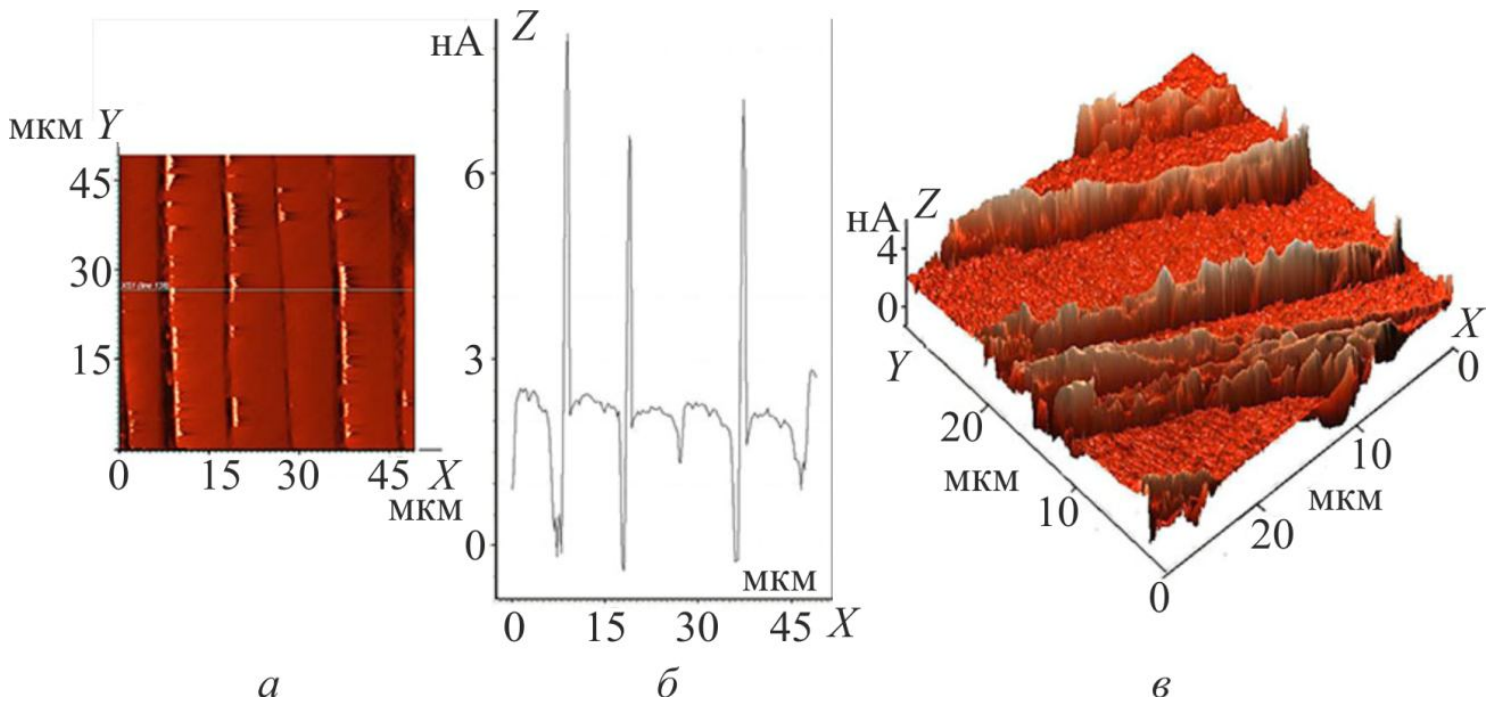

Рис. 2. Ниобиевый барьер вокруг волокон в матрице проводника в продольном сечении в исходном состоянии без шлифования в бездефектной области $(a)$; профилограмма этого участка (б); 3D изображение (в)

В ходе микроскопических исследований в промежуточном слое со стороны внутренней поверхности на границе с медным сердечником обнаружен специфический дефект в местах обрыва сверхпроводящих жил [12] (Рис. 3).

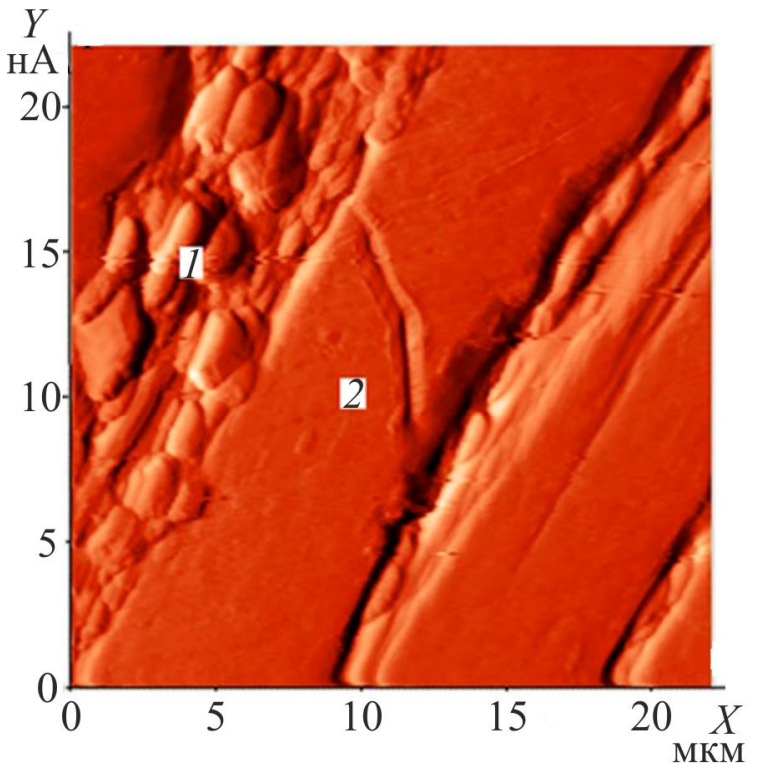

$a$

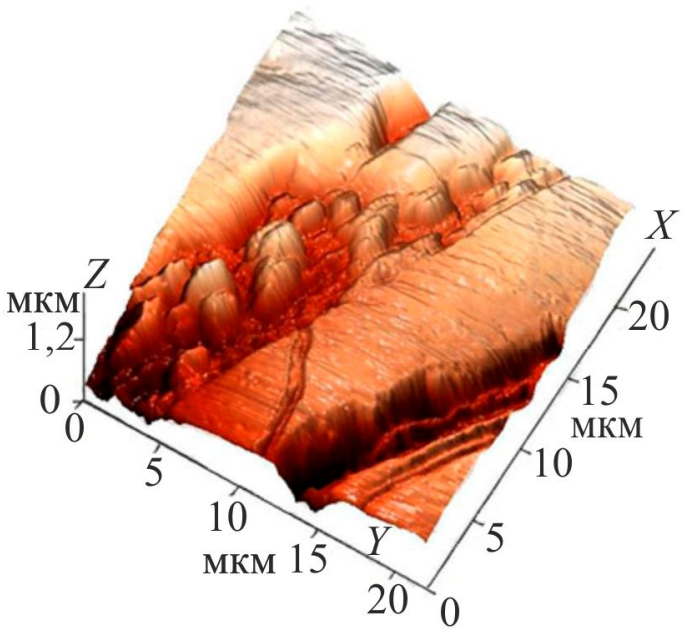

$\sigma$

Рис. 3. Обрыв волокна проводника в продольном сечении в исходном состоянии без шлифования в бездефектной области $(a)$; $3 \mathrm{D}$ изображение $(б)$; 1- медная матрица; 2 - волокно $\mathrm{Nb}-\mathrm{Ti}$

Исследования тонкой структуры элементов кабеля показали, что зона обрыва сопряжение границы волокно - матрица характеризуется частичным отсутствием ниобиевого барьера. Структура меди в медной матрице характеризуется как деформированная и релаксированная. Далее сопряжение границы матрица - волокно

Barannikova S.A. et al. / Studying the structure of the elements of the cable of technical superconductors by atomic force microscopy 
характеризуется наличием ниобиевого барьера. Структура $\mathrm{Nb}$ барьера субмикрокристаллисубмикрокристаллическая, зерна мелкие с незначительной неравноосностью.

Для исследования морфологии зоны обрыва по глубине шлифа снимали несколько раз слой на шлифовальной бумаге по 0,5 мм. Металлографические исследования показали, что со стороны внутренней поверхности, прилегающей к медному сердечнику, все волокна $\mathrm{Nb}-\mathrm{Ti}$ имеют округлую форму. Первые следы пластической деформации волочением наблюдаются в промежуточном слое в области, прилегающей к медной оболочке. Со стороны внешней поверхности волокна $\mathrm{Nb}-\mathrm{Ti}$ имеют форму в виде ромбов.

Топография поперечного сечения после шлифования на глубину 0,5 мм в месте обрыва проводника с использованием оптической и атомно-силовой микроскопии показала, что в области, прилегающей к медному сердечнику, близлежащие волокна $\mathrm{Nb}$-Ti имеют неправильную форму и образуют зону локализации деформации, как и в исходном состоянии без шлифования (рис. 4 a; 5 a). В месте обрыва проводника в матрице промежуточного слоя между $\mathrm{Nb}$-Ті волокнами средний размер зерна меди составил $>850$ нм. Следует отметить, что по результатам статистической обработки, в бездефектной области средний размер зерна меди в матрице 800 нм сопоставим с размером зерна меди 250 нм в месте обрыва проводника $[9,10]$. После шлифования поперечного сечения на глубину 0,5 мм в месте обрыва проводника вокруг волокон $\mathrm{Nb}-\mathrm{Ti}$, размещенных в медной матрице, обнаружен $\mathrm{Nb}$ барьер, который проявляется на профилограмме в виде высоких, тонких высокоамплитудных максимумов шириной до 250 нм, аналогичный ниобиевому барьеру в исходном состоянии без шлифования. Такой же $\mathrm{Nb}$ барьер обнаруживается вокруг волокон $\mathrm{Nb}-\mathrm{Ti}$ в месте обрыва после шлифования на глубину 1 мм.
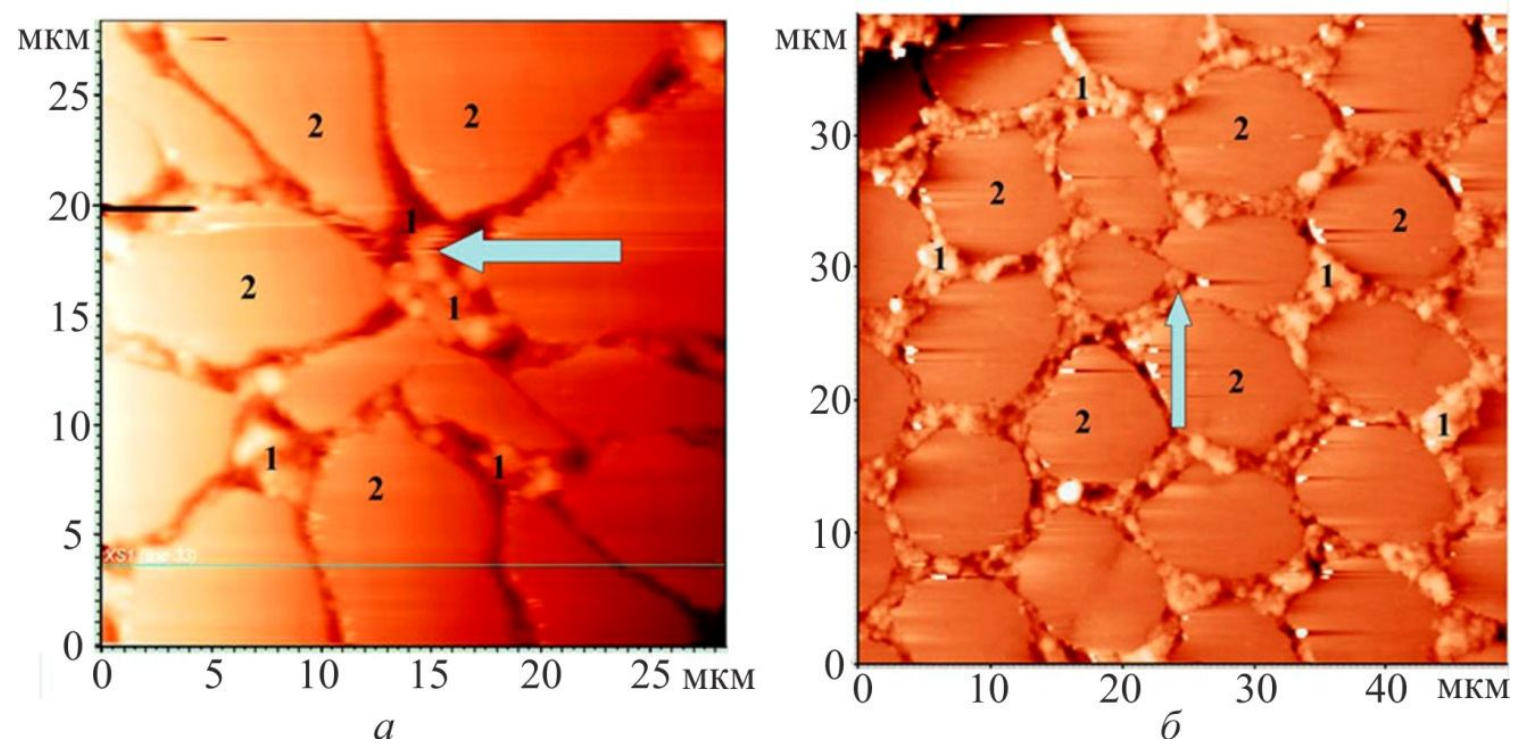

Рис. 4. Изменение зоны локализации пластической деформации в местах обрыва волокон $\mathrm{Nb}$ Ті проводника (указана стрелкой) по глубине шлифования, атомно-силовая микроскопия: $a-$ 0 мм, $6-2$ мм; 1- медная матрица, 2 - волокна $\mathrm{Nb}-\mathrm{Ti}$

Металлографические исследования поперечных сечений проводника после шлифования и травления на глубину 1 мм показали, что в бездефектной области общий вид $\mathrm{Nb}$-Ti волокон подобен исходному состоянию без шлифовки. В зоне обрыва происходит объединение вытянутых волокон в единую область, что указывает на неравномерный характер деформации волокон по длине провода. Близлежащие волокна $\mathrm{Nb}-\mathrm{Ti}$ в зоне локализации пластической деформации приобретают округлую форму.

Barannikova S.A. et al. / Studying the structure of the elements of the cable of technical superconductors by atomic force microscopy 


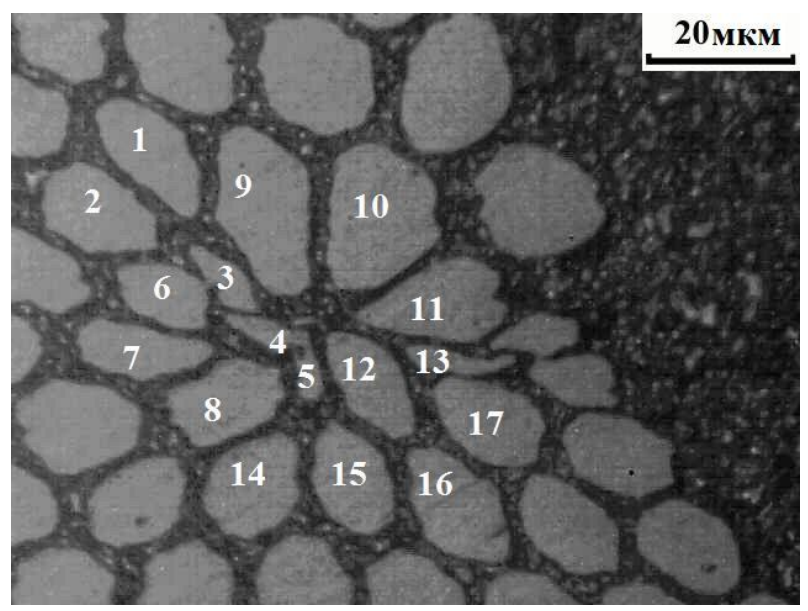

$a$

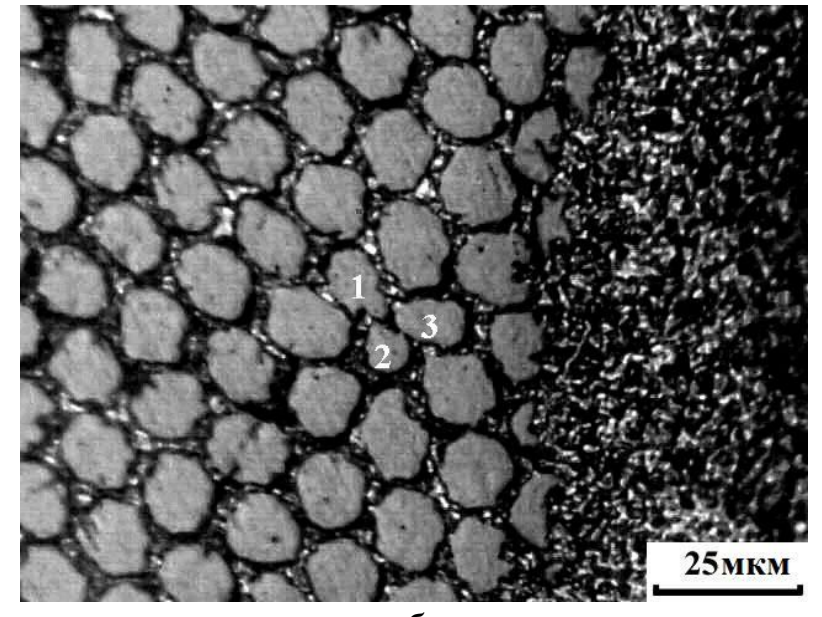

6

Рис. 5. Эволюция зоны локализации пластической деформации в местах обрыва волокон NbТі проводника по глубине шлифования, оптическая микроскопия: $a-0$ мм; $\sigma-2$ мм

Структурные исследования поверхности шлифа на оптическом микроскопе после шлифования на глубину 2 мм показали, что общий вид зоны локализации пластической деформации в виде дефекта по сравнению с исходным состоянием, существенно изменился. Волокна $\mathrm{Nb}$-Ті непосредственно в месте обрыва постепенно объединяются (рис. 4 б; 5 б), а близлежащие волокна $\mathrm{Nb}-\mathrm{Ti}$ вокруг дефекта имеют округлый вид, что характерно для волокон $\mathrm{Nb}$-Тi в бездефектной области. Следует отметить, что в другой области вблизи границы промежуточный слой волокон $\mathrm{Nb}-\mathrm{Ti}$ в медной матрице - медный сердечник обнаружен еще один дефект в виде двух волокон Nb-Ti меньшего размера и неправильной формы по сравнению с близлежащими волокнами $\mathrm{Nb}-\mathrm{Ti}$. Сканирование поверхности поперечного сечения шлифа с помощью атомно-силовой микроскопии “контактным методом“, после травления и шлифования на глубину 2 мм показало, что вокруг волокон $\mathrm{Nb}$ $\mathrm{Ti}$, размещенных в медной матрице, также наблюдается $\mathrm{Nb}$ барьер, который ранее обнаружен в исходном состоянии в бездефектной области без шлифования и проявляется на профилограммах в виде высоких, тонких высокоамплитудных максимумов шириной до 250 нм. $\mathrm{Nb}$ барьер также присутствует на всех $\mathrm{Nb}-\mathrm{Ti}$ волокнах сверхпроводника как со стороны внутренней, так и внешней поверхности волокон в медной матрице.

В основе подходов, традиционно используемых при анализе ресурса пластичности технических сверхпроводников на основе сплава $\mathrm{Nb}$-Ti [11], лежит представление о равномерности и однородности пластической деформации, о макромасштабной локализации непосредственно перед разрушением, что не соответствует современным представлениям. Экспериментальные данные о природе пластической деформации показывают, что присущая ей с самого начала деформирования неоднородность может приводить к раннему формированию одного или нескольких устойчивых очагов локализации пластического течения [11-13] и в дальнейшем - к обрыву жилы. Предпринятые в последнее время детальные исследования макролокализации деформации позволили установить однозначное соответствие между законом пластического течения на данном участке деформационной кривой и типом пространственно-временного распределения компонент тензора пластической дисторсии $[12,13]$. Эти факты должны приниматься во внимание при разработке технологии холодной деформации волочением до получения сверхпроводниковых жил требуемых размеров.

Barannikova S.A. et al. / Studying the structure of the elements of the cable of technical superconductors by atomic force microscopy 


\section{4. Заключение}

Проанализированы особенности тонкой структуры элементов кабеля технических сверхпроводников на основе ниобий-титанового сплава с использованием атомно-силовой микроскопии. Применение метода атомно-силовой микроскопии создает новые возможности для структурных исследований сверхпроводящих материалов на разных масштабных уровнях:

- в месте обрыва проводника выявлены зоны локализации деформации, в которых близлежащие волокна $\mathrm{Nb}-\mathrm{Ti}$ имеют неправильную форму при послойном шлифовании на глубину до 1000 мкм;

- обнаружено изменение размеров и формы волокон $\mathrm{Nb}-\mathrm{Ti}$ в промежуточном слое в бездефектной области; на границе с медным сердечником волокна имеют округлую, на границе с медной оболочкой волокна имеют ромбическую форму;

- в результате интенсивной пластической деформации медь в элементах кабеля приобретает субмикрокристаллическую структуру со средним размером: в сердечнике $\sim 800$ нм, в промежуточном слое между волокнами в матрице 800 нм, в месте обрыва проводника в промежуточном слое между волокнами в матрице $\sim 850$ нм, в оболочке $\sim 1050 \mathrm{нм}$;

- выявлен диффузионный $\mathrm{Nb}$ барьер вокруг волокон $\mathrm{Nb}-\mathrm{Ti}$, размещенных в медной матрице, шириной $\sim 250$ нм в бездефектной области и в зоне локализации пластической деформации при послойном шлифовании на глубину до 1000 мкм.

\section{Благодарность}

Работа выполнена в рамках Программы фундаментальных исследований Государственной академии наук в 2015-2020 гг.

\section{Литература}

1. Гинзбург В. Л., Андрюшин Е. А. Сверхпроводимость. - М. : Альфа-М, 2006. - 110 с. ISBN 5-98261-088-6.

2. Разработка сверхпроводников для магнитной системы ИТЭР в России / А. К. Шиков, А. Д. Никулин, А. Г. Силаев, А. Е. Воробьева, В. И. Панцырный, Г. П. Ведерников, Е. А. Дергунова, Л. В. Потанина, Э. И. Плашкин, С. В. Судьев // Известия вузов. Цветная металлургия. - 2003. - № 1. - С. 36-43.

3. Study on $\mathrm{I}_{\mathrm{c}}(\mathrm{T}, \mathrm{B})$ for the NbTi Strand Intended for ITER PF Insert Coil / Nina I. Kozlenkova, Gennadi P. Vedernikov, Alexander K. Shikov, Ludmila V. Potanina, Alexei V. Filatov, Alexandra E. Vorobieva, Viktor I. Pantsyrnyi, Igor N. Gubkin // IEEE Transactions on Applied Superconductivity. - 2004. - Vol. 14, no. 2. - P. 1028-1030. - DOI: 10.1109/TASC.2004.830385.

4. Lee P. J., Larbalestier D. C. Development of nanometer scale structures in composites of $\mathrm{NbTi}$ and their effect on the superconducting critical current density // Acta Metallurgica. - 1987. Vol. 35, iss. 10. - P. 2523-2536. - DOI:10.1016/0001-6160(87)90149-0.

5. Ниобий-титановые сверхпроводники с высокой токонесущей способностью / О. В. Черный, Г. Ф. Тихинский, Г. Е. Сторожилов, М. Б. Лазарева, Л. А. Корниенко, Н. Ф. Андриевская, В. В. Слезов, В. В. Сагалович, Я. Д. Стародубов, В. И. Савченко // Сверхпроводимость. Физика, химия, техника. - 1991. - Т. 4, № 8. - С.1617-1623.

6. Миронов В. Л. Основы сканирующей зондовой микроскопии: учебное пособие для студентов старших курсов высших учебных заведений. - Н. Новгород : ИФМ РАН, 2004. 110 с. - ISBN 5-948360-34-2.

7. Research of a microstructure of elements of a cable from a superconducting alloy of $\mathrm{Nb}-\mathrm{Ti} /$ L. B. Zuev, G. V. Shlyakhova, S. A. Barannikova, S. V. Kolosov // Russian Metallurgy. - 2013. Vol. 2013, iss. 3. - P. 229-234. - DOI: 10.1134/S0036029513030129.

Barannikova S.A. et al. / Studying the structure of the elements of the cable of technical superconductors by atomic force microscopy 
8. Шляхова Г. В., Баранникова С. А., Зуев Л. Б. Исследование тонкой структуры элементов кабеля технических сверхпроводников // Физика и химия обработки материалов. -2014. - № 4. - C. 80-88. - ISSN 0015-3214.

9. Шляхова Г. В., Баранникова С. А., Зуев Л. Б. Исследование наноструктурных элементов кабеля технических сверхпроводников $\mathrm{Nb}-\mathrm{Ti} / /$ Известия Вузов. Черная металлургия. 2013. - № 10. - C. 64-67. - ISSN 0368-0797.

10. Шляхова Г. В., Баранникова С. А., Зуев Л. Б. Исследование очагов локализации пластической деформации сверхпроводящего кабеля на основе сплава $\mathrm{Nb}-\mathrm{Ti} / /$ Металлофизика и новейшие технологии. - 2013. - Т. 35, № 4. - С. 453-465. - ISSN 1024-1809.

11. Phase composition, structure and plastic deformation localization in $\mathrm{Zr}-1 \% \mathrm{Nb}$ alloy / L. B. Zuev, S. Y. Zavodchikov, T. M. Poletika, G. S. Cheremnykh, V. B. Filippov, V. I. Belov, V. M. Arzhakova, O. V. Bocharov, A. K. Shikov // Zirconium in the Nuclear Industry: proc. $14^{\text {th }}$ Int. Symposium / Ed. by P. Rudling, B. Kammenzind. - West Conshohocken : ASTM. - 2006. P. 264-274. - DOI: 10.1520/STP37511S.

12. Зуев Л. Б., Данилов В. И., Баранникова С. А. Физика макролокализации пластического течения. - Новосибирск : Наука, 2008. - 327 с. - ISBN 978-5-02-023223-5.

13. Zuev L. B., Barannikova S. A. Experimental study of plastic flow macro-scale localization process: pattern, propagation rate, dispersion // International Journal of Mechanical Sciences. 2014. - Vol. 88. - P. 1-7. - DOI: 10.1016/j.ijmecsci.2014.06.012. 